Journal of Engineering and Applied Sciences 14 (Special Issue 8): 10467-10471, 2019

ISSN: 1816-949X

(C) Medwell Journals, 2019

\title{
Structural Dynamic Analysis of a Cross Country Mountain Bike Frame
}

\author{
${ }^{1}$ V. Kausalyah, ${ }^{2}$ S. Zulhilmi and ${ }^{3}$ S. Shasthri \\ ${ }^{1,2}$ Faculty of Mechanical Engineering, Universiti Teknologi MARA, \\ 40450 Shah Alam, Malaysia \\ ${ }^{3}$ School of Engineering and Physical Sciences, Heriott Watt University Malaysia, \\ Precint 5,62200 Putrajaya, Malaysia
}

\begin{abstract}
Bicycles continue to be a popular two wheeler mode of transportation even in the current era due to its nature in being environmental and entertainment friendly. This research in particular is conducted to study and analyze the structural stability of the cross country mountain bike frame with different rider loadings and materials. Three types of rider mass will be studied here, 60, 100 and $150 \mathrm{~kg}$, each representing the common, medium and higher extreme weight range of user. The load will be distributed in several percentage break ups on the seat, paddle and handle as described in the study. The mountain bike frames structural performance is also evaluated with three different materials applied, namely titanium, aluminum and carbon fiber. The structure consisting of a standard diamond-shape cross-country frame will be designed in a CAD modeling software, CATIA and pre-processed and post-processed in finite element simulation software, ANSYS. Analysis results from the numerical analysis are recorded in terms of stress plots, displacements and natural frequency values and mode shapes. Design optimization is performed on the regions indicating high stress plots to reduce the stress concentration and enhance the structural stability of the frame. Optimized design is validated again through numerical analysis.
\end{abstract}

Key words: Mountain bike frame, finite element analysis, dynamic analysis, design optimization, natural frequency

\section{INTRODUCTION}

The bicycle has affected history considerably in both culture and industrial realms. In early years of it invention, bicycle was constructed on pre-existing ancient technologies and it was increasingly developed each year. Due to the advent of modern material and computer aided design, the bicycle designs have changed with many practical improvements made. The varieties of bicycles available in industries nowadays and can be categorized in few different ways such as by function, number of rider, general construction, gearing or means of propulsion. The most famous types of bicycles commonly used are racing, mountain, touring, utility and sport bicycles. All of these bicycles are designed and manufactured based on its intended usage. For instance, racing bike needs to be aerodynamic and lightweight to gain maximum speed where else mountain bike needs to have high strength and agility to move quickly to avoid obstacles.

Thus, this research conducting the structural analysis will be able to determine the behavior of the mountain bike frame using static distributed load, natural frequency analysis to study the mode shape behavior and optimize the existing geometry of the frame designs to overcome the critical failure part based on static and frequency analysis.
Bicycle frame: Frame is the main component of a bicycle which it connected to the wheels and other components. The modern frame designs for mountain bicycle is based on the safety of the bicycle and consists of two triangles, a main triangle and a paired rear triangle. This type of frame shape is called the diamond frame (Brown, 2010; Pardeshi and Desle, 2014). Many type of shapes have been produced such as recumbent, monologue and folding frames. Cross-Country (XC) cycling is the most common discipline of mountain biking. The characteristic of cross country mountain bike frame is that it is light, nimble bikes best for competitive events featuring steep ascents and tight turns (Expert Advise, 2016). It's mass is typically between 7 and $16 \mathrm{~kg}$, usually featuring suspension forks in front and sometimes in the rear as well. It is not suited for the high jumps and impact landings. It is more focused on speed, cornering and ascending.

The usage of monocoque shape has been improved in mountain bike frame to make it stronger and stiffer. Leisha et al. have done research to determine the strain energy design method through the frame. The task was to improve the early prototype by using finite element analysis with the goal of refining a frame design which performed the same as the top-class steel frames of traditional design (Peterson and Londry, 1986). Thus, with the use of finite element method, early design errors can be detected rather than discovering them at the shop floor when it is too late. 
Geometry of the frame: Geometry is the set of all the measurements on a bike. Every angle and tube length is a part of a bike's overall geometry. Geometry affects the feel of a bike more than anything else. This is the reason we cannot take a cross country bike and turn it into a downhill bike. No matter how bombproof it is built, it will still feel out of place and awkward because the geometry is geared towards cross country. The geometry of the frame consist of several parts such as head tube, chain stay tube, seat tube, down tube, seat stay and top tube (Lin et al., 2017).

\section{MATERIALS AND METHODS}

The mountain bicycle frame will undergo several steps like sketching, design in CAD, material application testing three different materials and loading variations will be studied incorporating impact factor as well. Finite Element Analysis (FEA) will be carried out to study the stress plots and mode shapes before making any optimization for the frame. Designing the bicycle for performance or rider comfort is a more complex task than designing for sufficient strength, since, the interaction between rider and bicycle is involved (Lessard et al., 1995; Chang, 2002). Qualitative judgments such as 'too springy' or 'too stiff' must be quantified in terms of frame stiffness (Escalona and Recuero, 2012).

Here, the sketch will be determined by taking the actual dimensions from the cross country frame bicycle from one of leading mountain bike company where the frame has been used and tested already in the trail or track. The dimensions are as shown below. Carbon fiber has become one of the new evolving materials in bicycle frame fabrication. The structure of the carbon frame is similar to the racing bike structure. Three different common and popular materials which are used in the fabrication of the mountain bicycle is analyzed, namely aluminum, titanium and the emerging carbon fiber and the material properties are adapted from the standard table (Rontescu et al., 2015) (Fig. 1).

Loading and boundry conditions: Table 1 shows the mass distribution on a mountain bike frame. The weights are distribute through the test of weight distribution on bicycle where the rider is measured by the mass distribution from the body part such as arms, legs and upper body. The forces are distributed through 3 parts of the human body into the bike at handle bars, pedal and seat. During riding, the distribution are divided into percentages where the handle bar has $10 \%$ of the body mass, the pedal is asssigned 30 and $60 \%$ is assigned to the upper body at the seat. Three different rider weight is studied namely 60, 100 and $150 \mathrm{~kg}$ (an extreme weight to identify the stressed induced on the bike frame). Table 2 shows the proportions of weight distributed in the analysis. Figure 2 shows circular cross section frame with

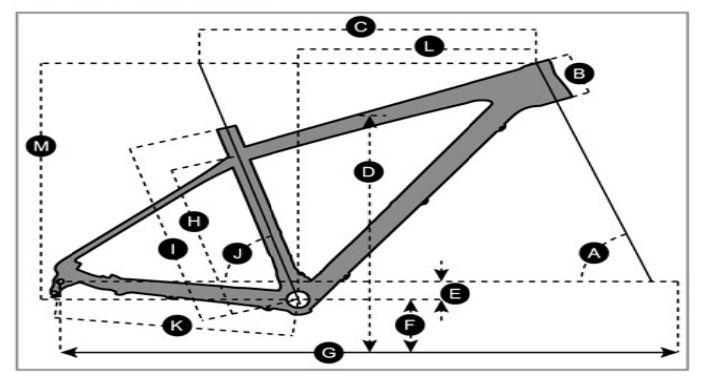

Fig. 1: The geometry of the mountain bike frame (Gupta and Rao, 2016)

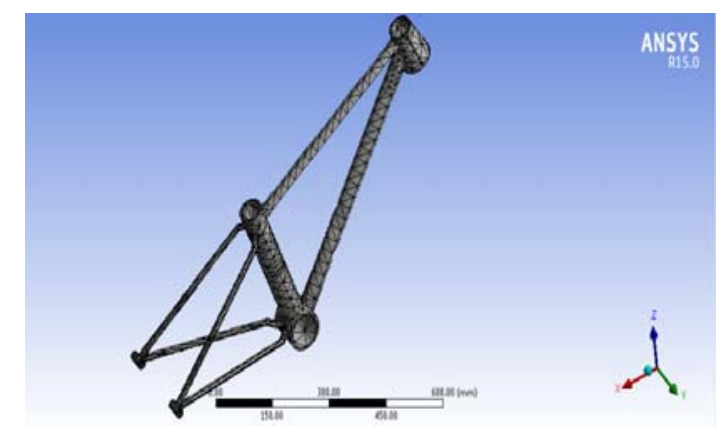

Fig. 2: Meshed model

Table 1: Dimension of bike frame

\begin{tabular}{lll}
\multicolumn{2}{l}{ Table 1: Dimension of bike frame } \\
\hline Alphabet & Geometry & Size S \\
\hline A & Head tube angle & $69^{\circ}$ \\
B & Head tube length & $100 \mathrm{~mm}$ \\
C & Top tube length & $575.0 \mathrm{~mm}$ \\
D & Stand over height & $728.9 \mathrm{~mm}$ \\
E & Bottom bracket offset & $-44.0 \mathrm{~mm}$ \\
F & Bottom bracket height & $307.5 \mathrm{~mm}$ \\
G & Wheel base & $1075.2 \mathrm{~mm}$ \\
H & Bottom bracket center to top tube & $315.8 \mathrm{~mm}$ \\
I & Bottom bracket center to top of seat tube & $390 \mathrm{~mm}$ \\
J & Seat angle & $73^{\circ}$ \\
K & Chain stay & $427.0 \mathrm{~mm}$ \\
L & Reach & $398.1 \mathrm{~mm}$ \\
M & Stack & $578.6 \mathrm{~mm}$ \\
\hline
\end{tabular}

Table 2: Weight distribution through mountain bike frame

\begin{tabular}{|c|c|c|c|c|c|c|}
\hline \multirow[b]{3}{*}{ Total rider mass, m (kg) } & \multicolumn{6}{|c|}{ Rider weight $(\mathrm{m} \times \mathrm{g})(\mathrm{N})$} \\
\hline & \multicolumn{3}{|c|}{ Without impact factor, $\mathrm{N}$} & \multicolumn{3}{|c|}{ With impact factor, $\mathrm{N} \times 2$} \\
\hline & Seat $(60 \%)$ & Pedal (30\%) & Handle (10\%) & Seat $(60 \%)$ & Pedal (30\%) & Handle (10\%) \\
\hline 60 & 360 & 180 & 60 & 720 & 360 & 120 \\
\hline 100 & 600 & 300 & 100 & 1200 & 600 & 200 \\
\hline 150 & 900 & 450 & 150 & 1800 & 900 & 300 \\
\hline
\end{tabular}


fine mesh (auto mesh). Figure 3 and 4 shows the fixed supports provided and the loading of $600 \mathrm{~N}$ is applied by static start up method on the bicycle frame.

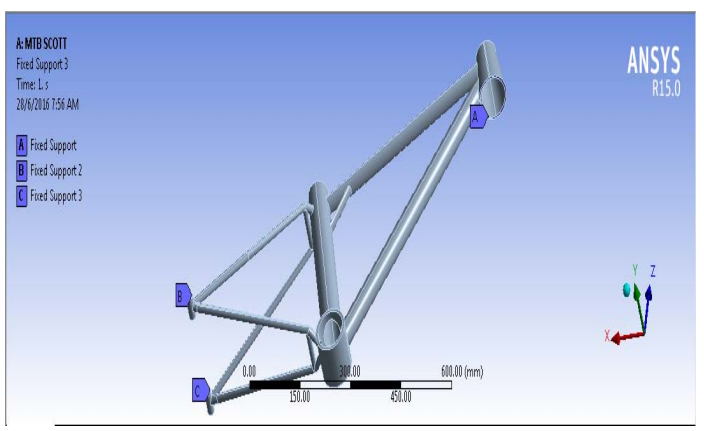

Fig. 3: Fixed support

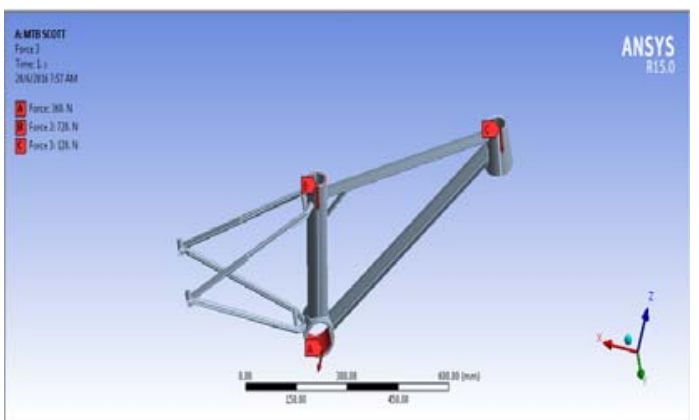

Fig. 4: Load condition

\section{RESULTS AND DISCUSSION}

Stress and frequency analysis: After the completion of pre-processing steps in ANSYS, analysis is performed and the following results in stress plots, deformation and frequency mode shapes are obtained. Illustrations of these plots are shown in Fig. 5a-d. It is observed that the frame with carbon fiber undergoes lesser deformation in comparison to the aluminium and titanium frames for all three rider mass regardless of mass computed with or without impact factor. Frequency analysis performed shows that not much changes are there in the frequencies from mode 1-10 for all the 3 rider's mass computed with and without impact factor. The increase of mass has little effect in the vibration of the frame (Table 3).

Optimization of the bicycle frame: Design optimization is conducted based on the results obtained from the stress, displacement and frequency analysis. A hollow tube with the size about $7 \mathrm{~mm}$ radius and $2 \mathrm{~mm}$ thickness is attached on at the chain stay tube and between the top tube and seat tube. Figure 6 and 7 illustrates the changes made. Similar stress and frequency analysis are performed on the optimized bike frame design and the results are recorded in Table 4.

Comparison of maximum stress and maximum displacement between aluminium, titanium and carbon fiber after optmization: From the stress values obtained after optimization an improvement of $2.32 \%$ for all three mass tested can be seen for the frame with

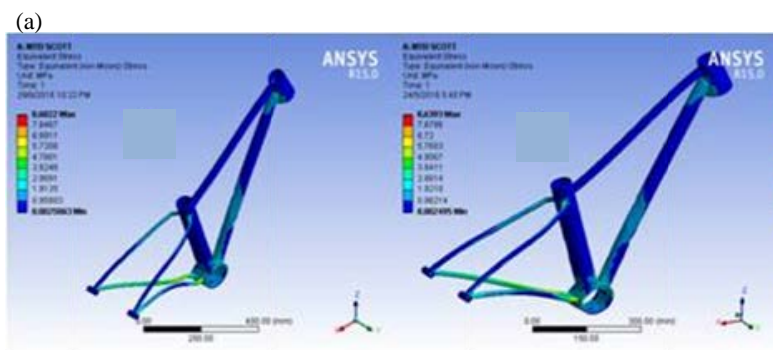

(c) (d)
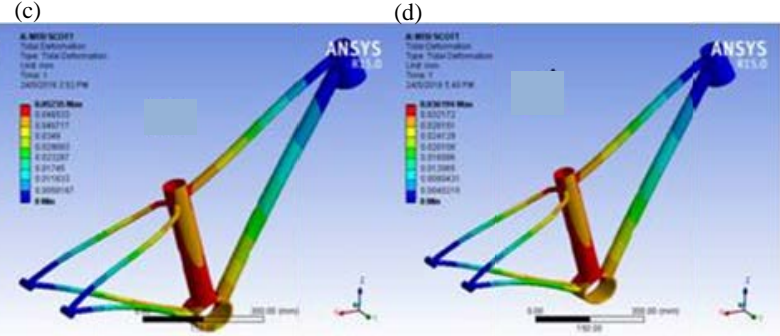

Fig. 5(a-d): Stress plots in aluminium, (b) Stress plots in titanium, (c) Displacement for aluminium and (d) Displacement for titanium

Table 3: Total maximum stress and maximum displacement

\begin{tabular}{|c|c|c|c|c|c|c|c|c|c|c|c|c|}
\hline \multirow[b]{3}{*}{$\begin{array}{l}\text { Total } \\
\text { rider } \\
\text { mass, } \\
\text { m (kg) }\end{array}$} & \multicolumn{4}{|c|}{ Aluminium } & \multicolumn{4}{|c|}{ Titanium } & \multicolumn{4}{|c|}{ Carbon fiber } \\
\hline & \multicolumn{2}{|c|}{ Without impact factor } & \multicolumn{2}{|c|}{ With impact factor } & \multicolumn{2}{|c|}{ Without impact factor } & \multicolumn{2}{|c|}{ With impact factor } & \multicolumn{2}{|c|}{ Without impact factor } & \multicolumn{2}{|c|}{ With impact factor } \\
\hline & $\begin{array}{l}\text { Total } \\
\text { max } \\
\text { stress } \\
\text { (MPa) }\end{array}$ & $\begin{array}{l}\text { Max } \\
\text { displacement } \\
\text { stress (mm) }\end{array}$ & $\begin{array}{l}\text { Total } \\
\text { max } \\
\text { stress } \\
(\mathrm{MPa})\end{array}$ & $\begin{array}{l}\text { Max } \\
\text { displacement } \\
\text { stress (mm) }\end{array}$ & $\begin{array}{l}\text { Total } \\
\text { max } \\
\text { stress } \\
(\mathrm{MPa})\end{array}$ & $\begin{array}{l}\text { Max } \\
\text { displacement } \\
\text { stress (mm) }\end{array}$ & $\begin{array}{l}\text { Total } \\
\text { max } \\
\text { stress } \\
(\mathrm{MPa})\end{array}$ & $\begin{array}{l}\text { Max } \\
\text { displacement } \\
\text { stress (mm) }\end{array}$ & $\begin{array}{l}\text { Total } \\
\text { max } \\
\text { stress } \\
(\mathrm{MPa})\end{array}$ & $\begin{array}{l}\text { Max } \\
\text { displacement } \\
\text { stress (mm) }\end{array}$ & $\begin{array}{l}\text { Total } \\
\text { max } \\
\text { stress } \\
(\mathrm{MPa})\end{array}$ & $\begin{array}{l}\text { Max } \\
\text { displacement } \\
\text { stress (mm) }\end{array}$ \\
\hline$\overline{60}$ & 8.602 & 0.053 & 17.204 & 0.105 & 8.639 & 0.036 & 17.279 & 0.072 & 8.717 & 0.030 & 17.434 & 0.061 \\
\hline 100 & 14.337 & 0.087 & 28.674 & 0.17 & 14.399 & 0.0 & 28.798 & 0.121 & 14.528 & 0.051 & 29.056 & 0.101 \\
\hline 150 & 21.505 & 0.131 & 43.011 & 0.262 & 21.598 & 0.091 & 43.196 & 0.181 & 21.792 & 0.076 & 43.584 & 0.151 \\
\hline
\end{tabular}




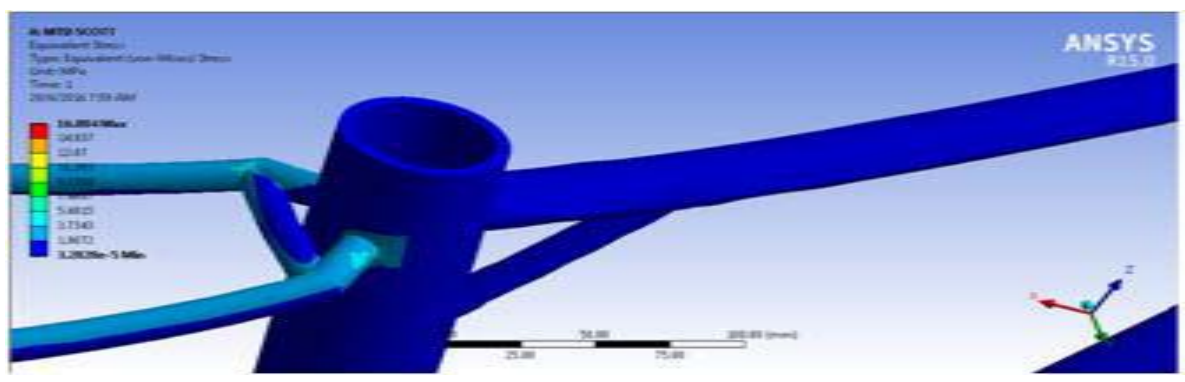

Fig. 6: Optimized area at top tube

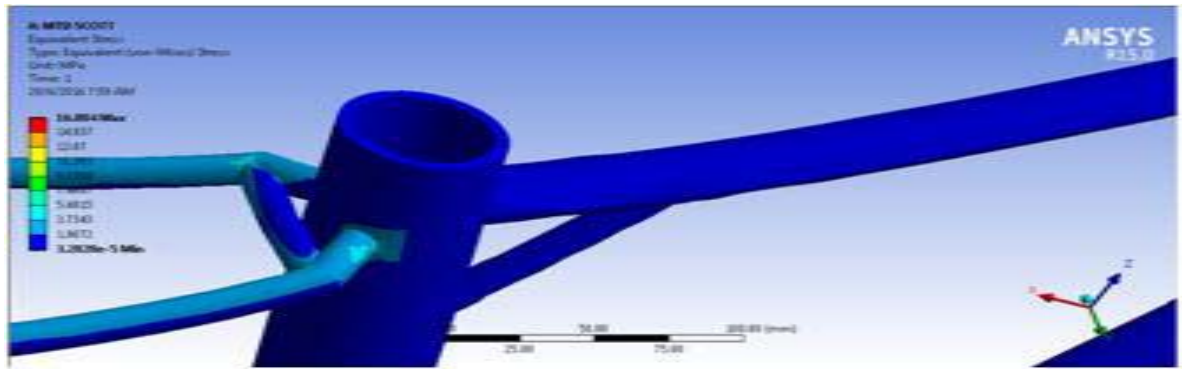

Fig. 7: Optimized area at chain stay
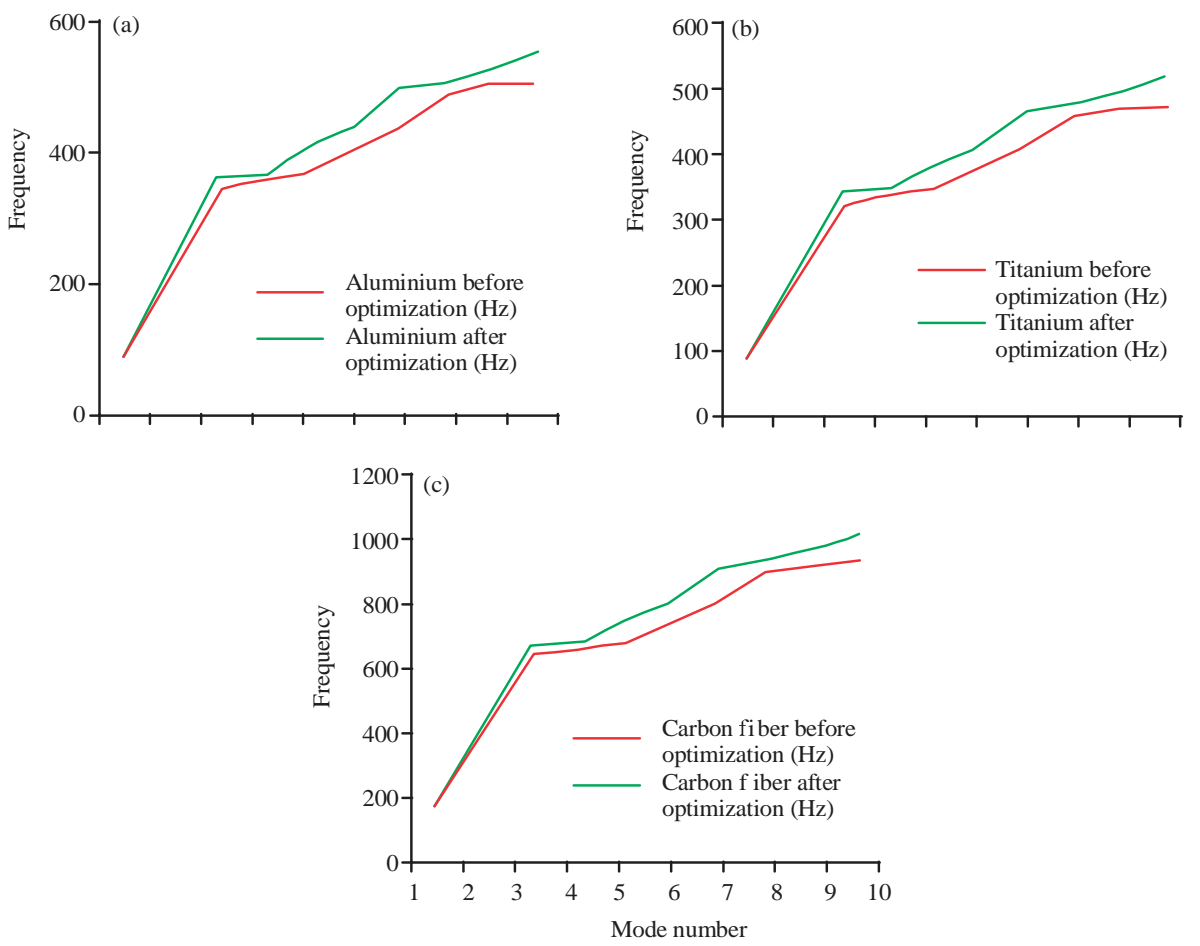

Fig. 8:(a-c) Comparison of frequency values for aluminium, titanium and carbon fiber before and after optimization

aluminium material, approximately $1.7 \%$ for titanium and $0.65 \%$ for carbon fiber. As for the displacement values, optimization shows an improvement an average of $3.84 \%$ for aluminium, $3.43 \%$ for titanium and $3.81 \%$ for carbon fiber. Carbon fiber exhibits the least amout of displacement indicating greater stiffnes in comparison to aluminuim and titanium.

Comparison of frequency between aluminium, titanium and carbon fiber: The graphs in Fig. 8 shows 
J. Eng. Applied Sci., 14 (Special Issue 8): 10467-10471, 2019

Table 4: Aluminium, titanium and carbon fiber max stress

\begin{tabular}{|c|c|c|c|c|c|c|}
\hline \multirow[b]{2}{*}{ Load $(\mathrm{N})$} & \multicolumn{2}{|l|}{ Aluminium } & \multicolumn{2}{|l|}{ Titanium } & \multicolumn{2}{|l|}{ Carbon fiber } \\
\hline & $\begin{array}{l}\text { Maximum stress } \\
\text { (MPa) before } \\
\text { optimization }\end{array}$ & $\begin{array}{l}\text { Maximum stress } \\
\text { (MPa) after } \\
\text { optimization }\end{array}$ & $\begin{array}{l}\text { Maximum stress } \\
\text { (MPa) before } \\
\text { optmization }\end{array}$ & $\begin{array}{l}\text { Maximum stress } \\
\text { (MPa) after } \\
\text { optimization }\end{array}$ & $\begin{array}{l}\text { Maximum stress } \\
\text { (MPa) before } \\
\text { optimization }\end{array}$ & $\begin{array}{l}\text { Maximum stress } \\
\text { (MPa) after } \\
\text { optimization } \\
\end{array}$ \\
\hline 600 & 8.602 & 8.4022 & 8.639 & 8.492 & 8.717 & 8.661 \\
\hline 1000 & 14.337 & 14.0040 & 14.399 & 14.153 & 14.528 & 14.433 \\
\hline 1500 & 21.505 & 21.0060 & 21.598 & 21.229 & 21.792 & 21.650 \\
\hline
\end{tabular}

that the optimization has more effect on the higher modes, mainly mode 5 onwards. This is same for all the three materials.

\section{CONCLUSION}

This research has outlined the finite element analysis of the cross country mountain bike frame. Structural dynamic analysis has been performed and the various stress and frequency analysis results have been recorded. In summary, the carbon fiber exhibits stiffer properties in comparison to aluminium and titanium. However, it is to be noted that all three materials present themselves valid for use in the production of the bike frame. The results of stress values are about the same for the three materials in each loading conditions tested. The load of $150 \mathrm{~kg}$ which is used to study the extreme rider weight condition indicates the highest stress values with $2.32 \%$ improvement in stresses in with the aluminium frame and $0.65 \%$ for the carbon fiber frame.

\section{ACKNOWLEDGEMENT}

The researchers would like to thank Universiti Teknologi MARA's Faculty of Mechanical Engineering and the Numerical Analysis Lab, FKM for their assistance in completing this research work. This research significantly adds academic value to the field of knowledge in mountain bike frame analyses and will potentially assist the industry in the manufacturing of such frames.

\section{REFERENCES}

Brown, S., 2010. Frame materials for the touring cyclist. Sheldon Brown CPA, LLC., Colorado, USA. https://www.sheldonbrown.com/frame-materials.ht $\mathrm{ml}$.
Chang, R.R., 2002. Finite element analyses and experimental considerations of the deflection and failure behaviour of an asymmetric laminate composite bicycle handlebar. Proc Instit. Mech. Eng. Part E. J. Process, 216: 207-218.

Escalona, J.L. and A.M. Recuero, 2012. A bicycle model for education in multibody dynamics and real-time interactive simulation. Multibody Syst. Dyn., 27: 383-402.

Expert Advise, 2016. How to choose mountain bikes. Expert Advise Inc., Owings Mills, USA. https://www.rei.com/learn/expert-advice/mountainbike.html

Gupta, R. and S. Rao, 2016. Analysis of mountain bike frame by FEM. IOSR. J. Mech. Civil Eng., 13: 60-71.

Lessard, L.B., J.A. Nemes and P.L. Lizotte, 1995. Utilization of FEA in the design of composite bicycle frames. Compos., 26: 72-74.

Lin, C.C., S.J. Huang and C.C. Liu, 2017. Structural analysis and optimization of bicycle frame designs. Adv. Mech. Eng., Vol. 9, No. 12. 10.1177/1687814017739513

Pardeshi, S. and P. Desle, 2014. Design and development of effective low weight racing bicycle frame. Int. J. Innovative Res. Sci. Eng. Technol. (IJIRSET), 3: $18215-18221$.

Peterson, L.A. and K.J. Londry, 1986. Finite-element structural analysis: A new tool for bicycle frame design. Bike Tech, Vol. 5,

Rontescu, C., T.D. Cicic, C.G. Amza, O. Chivu and D. Dobrota, 2015. Choosing the optimum material for making a bicycle frame. Metalurgija, 54: 679-682. 